\title{
CONSIDERING VALUES IN THE SPORT EXPERIENCES OF WHEELCHAIR BASKETBALL PLAYERS
}

original paper

( ) University School of Physical Education in Wrocław

DOI: https://doi.org/10.5114/hm.2018.73607

\section{KRZYSZTOF PEZDEK}

University School of Physical Education in Wrocław, Wrocław, Poland

\begin{abstract}
Purpose. The paper aims to discuss a diversity of sport experiences in individuals with physical disabilities who are members of a wheelchair basketball club. The sample of the study consisted of 10 males with physical disabilities (aged 18-40 years). Methods. The study used in-depth interviews, and a systems method was applied to analyse the interview data. The method allows for examining sport as a value which is neither fully autonomous nor predetermined.

Results. Despite the differences in the sample, it can be assumed that players with physical disabilities experience sport in similar ways. However, their experiences may differ in terms of kinds, forms, contents, positions, and functions of sport. This diversity represents the dynamics of relations, interactions, and interdependences among values in the participants' respective axiological systems. Besides, it also reflects the ways in which the participants perceive themselves in the context of multiple practices of daily life.
\end{abstract}

Conclusions. An essential difference between the experience of players from various countries may therefore lie chiefly in the context (e.g. social, economic, political) in which players function and in which they realize particular values. Further research should take this context into account and investigate in particular its dependencies and relations with other values, such as health, physical ability, work, education, etc. Also, research concerning how sport is experienced from the perspective of different types and levels of disability or from the perspective of gender could prove interesting.

Key words: sport, values, individuals with physical disabilities

\section{Introduction}

Individuals with physical disabilities often encounter difficulties developing positive experiences of their own bodiliness and social competencies. This is caused by a variety of factors, including their own self-perception and the societal beliefs about disability. Individuals with disabilities often perceive themselves as constrained by a number of health- and physical capabilities-related, educational, vocational, and other barriers, which are viewed as impeding their development [1]. In turn, societal beliefs picture individuals with disabilities as passive and less resourceful, and hence unable to develop the way able-bodied individuals do [2-5]. As a consequence, such experiences and societal beliefs breed many negative attitudes toward the physically disabled, including discrimination, de- valuation, exclusion, segregation, and stigmatization $[4,6,7]$.

One of the factors significantly affecting positive self-perception of individuals with physical disabilities is sport. Through involvement in sport activities, they may come to perceive themselves as more capable in daily life, more confident in their capacities, and more open to social interactions. Besides, sport may contribute to constructing new societal beliefs, in which the disabled are considered active partners in interpersonal relations, capable of taking care of themselves and others alike [2, 8-10].

In the value systems of individuals with physical disabilities, sport may take on a variety of kinds, forms, contents, positions, and functions. Sport may figure in them as an autotelic value or an instrumental one. Autotelic values are ends in themselves and, hence,

Correspondence address: Krzysztof Pezdek, University School of Physical Education in Wrocław, al. I.J. Paderewskiego 35, 51-612 Wrocław, Poland, e-mail: krzysztof.pezdek@awf.wroc.pl

Received: June 27, 2017

Accepted for publication: September 15, 2017

Citation: Pezdek K. Considering values in the sport experiences of wheelchair basketball players. Hum Mov. 2018;19(1):10-19; doi: https://doi.org/10.5114/hm.2018.73607. 
they are sought for themselves and not for the sake of any other value. In turn, instrumental values are employed as a tool in achieving other values [11]. In consistency with this approach, sport may figure in the life of an individual with a physical disability as a passion to be pursued as a desirable end in and for itself (an autotelic value) or, alternately, as a source of income and/or a pastime option complementing other values (an instrumental value) [12]. It should be borne in mind, though, that the proponents of instrumental values, e.g. pragmatists, tend to interrogate the viability of autotelic values. Such a position was embraced, for example, by Dewey [13], who took issue with the attribution to autotelic values of a transcendent existence beyond an empirical, researchable reality.

Sport may also appear in a variety of forms, e.g. as certain ideas, relations, beliefs, attitudes, goals, physical or mental states, etc., which a particular individual regards as a value. Hence, people with disabilities may view sport, for instance, as a religious idea which motivates them to perfect their skills, as a social relation which facilitates contacts with others, or as a goal to be achieved - e.g. winning a Paralympic medal [10, 14].

Depending on the context, sport may have various content ascribed to it. If sport is conceptualized in terms of vitality, the disabled involve in sport activities to improve their psycho-physical condition [15]. With the hedonic content foregrounded, individuals focus on the experience of pleasure derived from sport [2]. If sport assumes the utilitarian content, they pursue sport activity with particular gains in mind [12]. When the cultural content prevails, individuals see sport in terms of, for example, the idea of Olympism and symbolism of rivalry $[10,14]$. The religious content of sport is where people find a boost to their faith in supernatural powers [16]. And given the moral content of sport, they may become better humans by practicing sports [17].

Sport may take a central or a peripheral position in the value systems of individuals with physical disabilities. ${ }^{1}$ As a central value, sport essentially affects people's functioning by organizing their lives around the axis provided by this value and relegating other values to the margins of the axiological system. This happens, for example, when athletes are training for a tournament. They focus intensely on perfecting their psycho-physical condition and technical skills, with other values - family, education, jobs, etc. - thoroughly

${ }^{1}$ Some authors, e.g. Kluckhohn [18], examine the intensity of values rather than their position. However, irrespective of whether the position or intensity of values is studied, the definitions of central and peripheral values are, basically, the same. subordinated to the former goal [19]. In turn, sport as a peripheral value neither significantly influences one's functioning nor clusters around itself other values which could have such an impact. This is the case, for instance, when an individual with a disability finds education a supreme value and makes it central to their value system. In such an arrangement, sport may at best complement that central value, providing opportunities of active pastime or meetings with friends [20].

In the value systems of individuals with physical disabilities, sport may fulfil a number of functions:

- cognitive function - through sport, individuals gain self-knowledge and define their status in the society $[8,21,22]$;

- motivational function - through sport, individuals are motivated to act as well as to select methods and techniques for goal achievement and need satisfaction [2];

- educational function - through sport, individuals develop particular pro-social attitudes, e.g. fairness, responsibility [10, 17];

- expressive function - through sport, individuals manifest their emotional states [2, 8];

- health function - through sport, individuals relate to their own psycho-physical health [15];

- inclusive function - through sport, individuals join in the practices from which they were excluded owing to their illness or disability $[5,9,10]$.

The study aimed to explore how athletes with physical disabilities - members of a wheelchair basketball team - experienced sport. Depending on its kind, form, content, position, and function, involvement in sport tends to enhance the athletes' sense of self-worth and promotes social interactions with other individuals. Possible negative outcomes include a greater risk of injury or damage to health [15], but they tend to be downplayed and viewed as a 'price' to be paid for the possibility to practice sport. The research described below investigated first of all the ways in which athletes with physical disabilities experienced sport. Their experiences were not analysed by means of sociological or psychological quantitative assessment inventories.

Findings from this research may have implications for rehabilitation and inclusion of the disabled into the spheres of life from which they got excluded. They may also encourage national and local governments to promote disability sport as this leads to social integration and reduces socially harmful attitudes and beliefs about disability. Besides, the findings may also help develop interpersonal competencies of people who interact with the disabled both privately (family, friends) and institutionally (public agencies, sports clubs, companies, etc.). 


\section{Material and methods}

\section{Participants}

The sample of this study consisted of 10 wheelchair basketball players with physical disabilities (aged 1840 years; mean age, 30 years). All the participants were Caucasian male residents of the Lower Silesia province, Poland. Prior to the research, the participants were informed of its goals and each of them personally consented to participate.

A variety of disabilities were represented in the sample, including paraplegia $(n=5)$, unilateral lower limb loss $(n=4)$, and bilateral lower limb loss $(n=1)$. One participant reported having a disability at birth, and the remaining 9 acquired their disability after birth. The time period for the acquired disabilities ranged from 2 to 26 years.

All the participants had practiced wheelchair basketball for at least 1 year but not longer than for 26 years prior to the study (mean length of involvement in wheelchair basketball, 6 years). All the participants stated that they had been physically active before joining the wheelchair basketball team, citing predominantly recreational sport activity. The most popular sport in the sample was soccer, followed by basketball, weightlifting, kitesurfing, and tennis.

Despite the diversity in the sample, it can be assumed that players with physical disabilities experience sport in similar ways. However, their experiences may differ in terms of the kinds, forms, contents, positions, and functions of sport. This variety represents the dynamics of relations, interactions, and interdependences of values within the participants' axiological systems. Besides, it reflects their self-perception in the context of many everyday life practices.

The participants' experiences were examined qualitatively. Hence, effort was made to ensure that the respondents could speak 'in their own voices' and express their unique, individual sport experiences [2, 23-25].

The data analysis was guided by the systems method. The method allows for exploring sport as a value which is neither fully autonomous nor entirely predetermined since, in consistency with the systems approach, it is involved in a network of relations, interactions, and interdependences with other values, as well as with the value system as a whole [26]. Hence, the relations, interactions, and interdependences keep affecting the kinds, forms, contents, positions, and functions of sport. The systems analysis of the findings reveals the diversity and dynamics of meanings conferred on sport rela- tive to various contexts, which, additionally, may overlap and intersect. ${ }^{2}$

\section{Instrument}

Information about the sport experiences of the athletes with physical disabilities was obtained with the use of in-depth interviews conducted with them. The interview guide included one general question: 'Can you tell me about your sport-related experiences?' It was followed by other questions, designed to encourage the participants to elaborate on the issues they addressed. The questions concerned time (when?), place (where?), other people and things involved (who? what?), and reasons (why? how?). In this way, descriptions of the participants' experiences were obtained, as well as interpretations were elicited of the issues mentioned as embedded in particular spatial and temporal contexts. $^{3}$

The objectives and design of the study were approved by the Senate Research Ethics Committee of the University School of Physical Education in Wrocław, Poland. The research concept was also appreciated by the coach of the wheelchair basketball team, who additionally suggested that the study should be carried out during a practice camp at the training centre. When participating in the camp, the players were accommodated and practiced at the centre for a whole week, which provided a favourable setting for the interviews.

\section{Procedure}

The athletes were informed about the objectives and overall design of the study and, after agreeing to participate, they were introduced to specific details and given the opportunity to choose the interview times and venues that suited them best. Four participants chose to do the interview after the morning practice session and before lunch, while 6 others chose the time between the evening practice session and supper. All the participants preferred to be interviewed in their accommodation facilities at the training centre. The interviews were conducted over two days during the practice camp.

\footnotetext{
${ }^{2}$ I have also dealt with the value systems of people with disabilities playing wheelchair basketball in two other papers [27, 28].

${ }^{3}$ The most important feature of the in-depth interview is the possibility of narrative reaching the experiences of people with disabilities [29]. I have written more about applying this qualitative method in studies among people with disabilities in the 'Physiotherapy' [30] and 'Nursing Philosophy' [31] journals.
} 
The interviews were conducted by two persons. Both of them had Ph.D. degrees in the humanities and had done research on disability previously. Also, they had experience with qualitative research methods. Each interview took between one and two hours and was tape-recorded to make sure that the participants felt as comfortable as possible in their responses. At any time, the participants could interrupt the interview and resume it later or give up on it altogether. All the personal data were coded so as to ensure complete anonymity of the participants (as stipulated by the Polish Personal Data Protection Act of 29 August 1997; Journal of Laws 1997, No. 133, item 883).

All the recorded interviews were transcribed into text format so as to assure their accuracy. Subsequently, the two researchers-interviewers conducted independent content analyses of the 10 transcriptions. The question that guided the analysis related to identifying the diversity of sport experiences in the wheelchair basketball players. The emerging themes were classified into 3 groups: (a) sport as a goal, an autotelic value, and an instrumental value; (b) sport as a central value and a peripheral value; (c) functions of sport in the experiences of the wheelchair basketball players.

In order to enhance the trustworthiness of findings in terms of credibility, transferability, dependability, and confirmability, several features were included in the study design: (a) open-ended questions were used in the interview so as to give the participants the opportunity to freely express their experiences; (b) the interviews were administered by experienced researchers; (c) comfortable interview atmosphere was created in which the participants were in full control of the situation; (d) in the data analysis stage, full transcriptions of the recorded interviews were used; (e) the two researchers coded and analysed the interview data independently; (f) both positive and negative sport experiences of the players were probed for and explored; (g) the participants verbatim responses were used to illustrate the diverse ways in which sport was experienced.

\section{Ethical approval}

The research related to human use has been complied with all the relevant national regulations and institutional policies, has followed the tenets of the Declaration of Helsinki, and has been approved by the authors' institutional review board or an equivalent committee.

\section{Informed consent}

Informed consent has been obtained from all individuals included in this study.

\section{Results}

The interview responses revealed a few common patterns in the sport experiences of the wheelchair basketball players. Direct quotes are used below to demonstrate how sport is experienced in terms of kind, form, content, position, and function.

Sport as a goal, an autotelic value, and an instrumental value

In the experiences of athletes with physical disabilities, sport as an autotelic value was present first of all in the form of goals. When the goals adequately corresponded to the contexts in which the players functioned, goal achievement enhanced their positive selfperception and involvement in social interactions. Such experiences relative to sport were confirmed by a number of participants. One of them was a 40-year-old player with unilateral lower limb loss who had been passionate about sport and looked for a suitable sport to practice ever since childhood: 'As early as in primary school, I landed up at a chess club and once the coach invited me to take part in a Children's Day contest. Basically, all the club members lost, only two chess-players were better than me.' However, he realized relatively soon that chess was not a good sport for him as it did not give him the much wanted opportunity to move. Consequently, as a vocational school student, he picked up handball. It was a rather surprising choice given that he had been born without one lower limb and walked on crutches or used a prosthesis. Yet the dysfunction did not seem to interfere with playing as a goalkeeper. He was even voted the best goalkeeper at one of the tournaments he played: 'It was the first time in the school league history that my team won against such a strong team. That team, from High School Number One, was the best one in those days. They were so good they could've played in the regular league. And we won against them! The visiting team failed to score three penalties with me defending. A pal of mine executed them, I knew him from the neighbourhood. He comes up to me later and goes: "Man, how did you pull that one off?" And they were the only three penalties he didn't score in the whole tournament. Certainly, that gave me a real boost.' Having practiced handball for 3 years, the player concluded that the sport was not good for him, either. That time, insufficient movement was not an issue, as was in the case with chess; he seemed to have a problem with his prosthesis: 'Playing handball, I had a prosthesis which could bend, just like a leg, but the problem was that after 
a few games it was only good for repair. Well, it wasn't perfect anyway, but it did bend. Frankly, I found it kind of inconvenient 'cause when I leaned on it, I wasn't fully stable. But I could handle it somehow.' The player's subsequent choice concerning sport was wheelchair basketball. That he started it was actually a matter of coincidence. Close to where he lived, a wheelchair basketball team held its practice sessions, and one of the players approached him in the street one day: 'I remember, first it was a shock of sorts. I came over, saw the wheelchairs, and said: "Gentlemen, it's not for me." But I sat down with them once, then again, and somehow I stuck around and have played for 25 years now.' Ever since joining the team, the athlete has given precedence to basketball over other things in life. Important though they still might be, other values, such as music, must give way to the sporting passion: 'Whenever I had a choice between a game and a concert, I would end up playing the game.' Having practiced wheelchair basketball for 25 years, the player openly admitted: 'If you want to play, you must love it, you must be an aficionado.'

In the experiences of the 40-year-old player with unilateral lower limb loss, sport was an autotelic end, with all other ends (e.g. music) subordinated to it. Admittedly, he has shifted sport disciplines a few times, but he has always been certain that he will continue practicing sport as such. Similar views were also articulated by other participants. In his response, an 18-year-old athlete with paraplegia said: 'I've always looked for opportunities to be active, possibilities to practice sport. Earlier, I was just a supporter of Śląsk Wrocław. ${ }^{4}$ We had free tickets and passes. We had transportation, basically everything it took to go and root for our team.' But later he moved to another town, where he met a coach who invited him to join a wheelchair basketball training session: 'I loved the practice, so I stayed for good. I've been training for 2 years now, and I see that I'm stronger and can go out on my own. Earlier, my parents had to carry me or push the wheelchair.' In this case, fascination with sport evolved from passive involvement (cheering for the team) to active participation (practicing basketball). Still throughout the process, sport was a goal whose content underwent modifications depending on the context in which the player functioned. In his being a supporter, sport accrued hedonic content (pleasure from rooting for the team), while in practicing basketball, the vital and utilitarian aspects prevailed, with the player perclub.

\footnotetext{
${ }^{4}$ Wojskowy Klub Sportowy Śląsk - Wrocław's biggest sports
}

ceiving himself as more capable or viewing sport in terms of practical gains (e.g. being able to go out without other people's help).

However, sport as an autotelic value might be also at odds with the contexts in which the athletes with physical disabilities functioned. If this was the case, goal achievement neither enhanced their adequate selfperception of their psycho-physical capacities nor promoted their greater involvement in social interactions. The examination of the participants' responses implies that only one respondent - a 33-year-old male with paraplegia - had such experiences: 'Ever since I can remember, I've been an active person. I think that in this respect I stood out from my peers. I lived in a small town near Wrocław, and already as a young child I practiced football in many clubs, even in Wrocław.' Poignant and symptomatic was his assertion: 'In terms of fitness, I thought I was indestructible, I could practice many sports at the same time.' These words imply that, in a sense, the player perceived himself as a 'superman.' And it did not take long until he subordinated his entire life, including education and friendship, to sport: 'I wasn't a good student, I found learning boring, I preferred physical activity. I wanted to be a professional athlete. I practiced so much, it was simply overwhelming. Sport got the better even of parties, I preferred training to meeting up with my friends.' The pursuit of goals divergent from the context in which the player functioned brought about a disastrous accident. At a kitesurfing camp, he ignored adverse weather and failed to properly adjust his sport gear to the atmospheric conditions. A sudden blast of wind made him lose control of the sail, and pushed violently to the shore, straight onto metal railings. As a result of the impact, his spinal cord was broken, which led to lower limbs paresis. Nonetheless, on waking up from anaesthesia, the participant asked first thing whether he would be able to use a wheelchair as he realized that should it be the case he could find a fitting sport to practice. His choice was wheelchair basketball.

In the experiences of the 33-year-old player with paraplegia, sport became a goal pursuing which did not produce the desired outcomes. One of the reasons for that was his self-perception as a 'superman' who could train practically any sport, irrespective of the psychophysical, organizational, equipment-related, or financial realities. The participant also did not seek to enter sustained interpersonal relations since most of his time was devoted to sporting activities.

However, in the experiences of the majority of the participants, sport turned out to be an instrumental value; they neither viewed it as an autotelic end nor at- 
tributed metaphysical content or supernatural properties to it. They focused, namely, first and foremost on its utilitarian, hedonic, and vital dimensions. Conceived in this way, sport was treated as a tool to be used in pursuing other values, therein values unrelated to sport activities. For example, the athletes emphasized in their responses that sport was a tool to improve their physical capabilities. It made them more skilful and fitter in practices of daily life, and increased their quality of life. This aspect was articulated by an 18-year-old player with paraplegia: 'Now I can walk on crutches on my own. I can even sit up straight. Sport is rehabilitation, but you need to exercise a lot, 45 minutes or even an hour each time. Once my parents used to carry me, and now I grab the crutches, and climb up to the second floor all by myself. I can go up the stairs on my own, and am not a burden to my parents any more.' Similar themes emerged from the responses of the other players of the team as well. The issue was voiced the most powerfully by a 40 -year-old player with unilateral lower limb loss: 'Once, a boy joined us in a practice session who'd been in a very bad accident. He'd injured his spinal cord in the neck. So in that first training he could throw the ball up with his two hands, what, some 8 inches high, not more. That's how badly paralysed he was. But, look, he didn't skip a single practice session. He wanted that badly, and he saw what effect it had on him. So towards the end of his playing, somewhere around 2000, he regularly made 3-pointers. That's how able it'd all made him [...]. For me, the boy was a true specimen, really. He always came to train of his own accord. Nobody forbids anybody to practice. If the team isn't complete, you can join us to go and play a tournament. Nobody actually counted on that man, that he would ever play with us, but a moment came that he was in our starting lineup actually. He developed such skills and ability that... well, you could see what he'd trained for.'

In these players' experiences, sport accrued an instrumental value, which helped them improve their physical capabilities and, consequently, facilitated goal achievement outside the realm of sport. Each of the respondents admitted that, besides being a vehicle of strictly sporting values, training at the club met their need for rehabilitation (vital and hedonic value), which was otherwise difficult to secure. This theme appeared in the response of a 30-year-old player with paraplegia: 'People in wheelchairs must exercise 'cause the whole body works differently then. Movement is essential. Everybody must take care of their own development. The state doesn't provide rehabilitation all the time, only just after the accident, at big rehabilitation facilities they work in a wholesale mode while everybody has a different therapeutic problem. Everybody needs individualized approach. Rehabilitation in Poland is poor. It's not adjusted to a person's age or particular needs.'

All the participants had aspired to become professional athletes, but soon enough they realized that it was very challenging in Poland. This observation was expressed by a 40-year-old player with unilateral lower limb loss: 'It'd be nice if one could do basketball only, without thinking that there's the home to provide for, shopping to do, bills, it'd be great, but unfortunately that's not the way things are.' For that reason, only a 22-year-old player with bilateral lower limb loss and an 18-year-old player with paraplegia turned professional. Both got national team appointments, and signed contracts to play for foreign clubs. The remaining participants combined their sporting passion with jobs.

\section{Sport as a central value and a peripheral value}

Comparisons of the athletes' responses imply that the participants who perceived sport as an autotelic value made it a central point of their interests and pursuits. That is why other values (e.g. education, vocational career, etc.) were relegated to the peripheries of their axiological systems. This was confirmed by the story of a 22-year-old player with bilateral lower limb loss: 'After practice, I don't have it in me to learn any more. The teachers thought I was simply lazy. They'd say I was clever but didn't bother to study. This year I take my A-levels. The teachers say that studying is important, but I learn only what I've really got to.' And a 33-year-old player with paraplegia admitted explicitly: 'Sport outdid even social life.' In turn, a 40-yearold player with unilateral lower limb loss observed that disability sport attracted predominantly aficionados, who did not care a lot about earnings: 'If you wanted to take up basketball, you shouldn't expect money from it. It's not a sport that brings money. You put your own money into it.'

What the athletes found essential was simply involvement in sport activities regardless of its circumstances and forms. If their physical status made them unfit for elite professional sport, they would certainly opt for amateur sport. And if they could not practice amateur sport, they would be fervent supporters cheering for their beloved teams. In this case, the players invested primarily vital and hedonic content with sport and, secondly, attributed a social dimension to it. Sport, namely, enhanced their self-perception as members of the basketball team, weakening at the same 
time their self-perception in other social roles, for example, of students, friends, and employees. The participants did not fully identify with those roles and, consequently, performed only at the minimum necessary level in them.

The situation was radically different for the players who viewed sport as an instrumental value. In their case, sport did not lie at the centre of their lives, and they associated their future with the pursuit of other values. Such sport experiences emerged in the responses of some participants. One of them was a 27-year-old player with unilateral lower limb loss, who asserted: 'Basketball isn't my life's end goal, for me it's all about fun, pleasure. Traveling across Poland is fun. If you win, you go celebrating. But come Monday, you must go to work. You can't really go the full monty, but I, for one, have no complaints.' Similar tones reverberated also in the response of a 30-yearold player with paraplegia: 'Basketball is rehabilitation and a social occasion. In practice, I can get my body moving, which is particularly important if you work at the desk.'

Hence, if sport and other values came to a clash, those players tended to prioritize the other values. Such choices were reported by a few respondents, therein a 39-year-old player with unilateral lower limb loss: 'My work was on a collision course with the national team's training camps. The boss wouldn't have me skipping work for weeks on end. And so my work put my rendezvous with the national team to an end rather quickly.' In this case, sport came to be subordinated to the demands of the athlete's job. With the job on his mind, he decided to quit playing for Poland's national team, but he remained in a team whose practice sessions did not interfere with his work duties.

In the value systems of those players, sport occupied a peripheral position, while central to them were mainly jobs. This, however, does not mean that sport was of no consequence to the athletes. On the contrary, they admitted that sport gave them the opportunity to spend leisure time actively, to obtain free rehabilitation, to travel, and to expand social life. In this case, the players attributed vital, hedonic, and, primarily, social content to sport. Namely, sport enhanced their self-perception as employees and, at the same time, as players, friends, or participants in the social life.

Functions of sport in the experiences of the wheelchair basketball players

In the participants' lives, sport fulfilled a multiplicity of functions both at the individual and at the social levels. In their responses, the respondents highlighted, among others, cognitive and motivational functions. The two enabled them to find out about their own capabilities in new contexts and settings, as well as to put them to good use. A 33-year-old player with paraplegia admitted: 'Without sport I'd take much longer to do shopping, to put the foods into the fridge at home, well, I do that riding so to say, but my whole body works, after all I push the wheels with my hands. I need to be in good shape!'

Realizing the extent of their psycho-physical limitations motivated the players to take better care of themselves. This aspect was highlighted by a 35 -year-old player with paraplegia: 'I'm now more vulnerable to various infections, it gets on my nerves but also motivates me to take better care of myself. I must be more cautious. All sorts of injuries heal differently 'cause the whole body works differently, the leg bones look different, they're weaker.'

The participants achieved self-knowledge, among others, through involvement in sport activities. For example, they noticed that because of the disability, everyday routines took much longer than before. At the same time, they admitted that this realization prompted them to work more on their psycho-physical fitness because that helped them overcome the limitations.

Besides, the respondents admitted that active involvement in one sport prompted them to open to other sports as well. This theme emerged in the responses of a few participants, therein a 30-year-old player with paraplegia, who took up diving and swimming: 'Simply, I wanted to swim. But they go about it differently now. I have this pull buoy that helps me keep my legs up afloat, and you swim using your arms only.' And a 32-year-old player with unilateral lower limb loss learned monoskiing: 'It wasn't an easy thing to learn, but I dug my heels in and finally started to ski.'

Another function of sport addressed by the participants was education. Sporting rivalry taught them solidarity and loyalty to the team. This was mentioned by a 40 -year-old player with unilateral lower limb loss: 'You know how things are in team sports. There're, say, 10 of us, and each has a different temperament. The point is to get adjusted to each other. Without one dominating another but so as not to get in each other's way. On the floor, the team must be a monolith, happen what may, it must remain so.' Besides, being a member of the team taught the players to be responsible for others. An 18-year-old player with paraplegia emphasized that in his response: 'It's not a problem for me that I'm weaker. Every now and then I can't get this or that right, then others'll help me. They'll give me 
tips, the coach, my pals will. They explain how to block, dodge, shield myself. It's a team sport so we must help and advise each other.'

Sport's expressive function also surfaced in the players' responses. It helped them manifest their emotions and attitudes about multiple facts, phenomena, or developments. For example, a 40-year-old player with unilateral lower limb loss explained: 'I've always found basketball fun, not only in the sense of sitting in front of TV and watching a game, but also playing it.' And a 22-year-old player with bilateral lower limb loss admitted that practicing sport provided him with the only opportunity to experience a sense of achievement: 'Basketball is important for me. I keep improving. When playing, I don't think about anything else. I've known no other success but basketball.' In turn, an 18-yearold player with paraplegia highlighted the possibility of experiencing and expressing strong emotions through sport. This is how he reported his joy from playing in an international tournament: 'I shot a basket! I was so happy that I could hardly go back and play in my defence position!' And he described his emotions after a loss in the following way: 'I was very sad because I gave it my all, but we lost anyway.'

In the players' responses, sport's health function was mentioned primarily in the context of additional rehabilitation opportunities. Each of the participants admitted that regular practicing improved their psychophysical status. This was mentioned by, among others, an 18-year-old player with paraplegia: 'Once my parents used to carry me, and now I grab the crutches, and climb up to the second floor all by myself. I can go up the stairs on my own, and am not a burden to my parents any more.' A 27-year-old player with unilateral lower limb loss affirmed explicitly: 'Doing a sport makes me feel more capable.'

Admittedly, 2 participants also observed that sport involved not only possibilities of improving one's fitness but also a greater risk of injury. This was mentioned by a 40-year-old player with unilateral lower limb loss: 'My health isn't what it used to be any more. Unfortunately, I already feel injured joints, injured backbone. Unfortunately, everything comes at a price, quid pro quo.' And a 33-year-old player addressed the issue of ethical principles in today's sport: 'Sport federations are interested in making sport as spectacular as possible and attract as many sponsors as possible. Nobody really cares about the fair play rules. As I see, it's all about having the possibly fittest people do sports and score possibly high. The same as in able-bodied sport. I suspect there might be some doping deals in sports that rely mainly on strength and endurance. That's the same kind of sport.'
The last function of sport reported by the athletes with physical disabilities was the inclusive function. Through sport, the players could again get involved in everyday practices and routines from which they had been excluded owing to disability. Such expanded involvement was mentioned by, among others, a 22 -yearold player with bilateral lower limb loss: 'Earlier I had very few friends, and barely met up with people. Through basketball, I've met a lot of Poles who've played abroad. We keep e-mailing each other, but also visit each other. And thanks to that I may even see some of the world.' And a 39-year-old player with unilateral lower limb loss stated that pursuing sport activities expanded also his social life: 'Before I joined the team, my life was like work and home only. It's different now. After the game, we sit down together, the whole team, have a beer or two. Our families meet as well, birthdays, holidays, barbecues. They like each other.' In turn, a 33-year-old player with paraplegia said: 'Now everybody has a job 'cause they're more self-confident. Rarely in a protected labour company. We function normally in the society, and don't care whether a person is in a wheelchair or not.'

The analyses of the participants' responses imply that sport largely impacted interpersonal contacts and social integration. Besides, sport activity enhanced the players' confidence as employees and made them more eager to seek employment in regular rather than in protected labour companies.

\section{Discussion}

On the basis of the research findings, it could be inferred that sport assumed particular kinds, forms, contents, positions, and functions depending on the contexts in which the participants functioned. This diversity, however, does not preclude more generalized conclusions about how the players with physical disabilities experienced sport.

First of all, the participants' responses imply that they did not perceive sport practice as an elite activity to be pursued by few only. The athletes, namely, viewed sport primarily as providing additional rehabilitation and the opportunity to go out, experience emotions, socialize, meet new people and/or travel. That is why they did not experience sport exclusively as a rivalry-oriented autotelic value focused on struggling for the best score. In their responses, they concentrated rather on instrumental values, which facilitated achievement of other goals, unrelated to sport. Hence, they invested sport predominantly with vital content (more capable bodies), hedonic content (pleasure from 
sport practice), and utilitarian content (opportunity to socialize or travel). For this reason, sport, as a rule, occupied a peripheral position in their axiological systems, with the central position ascribed to jobs. As a peripheral value, sport enhanced the players' selfperception in various social roles, such as an employee, a friend, or a participant in social occasions. Only few respondents found sport central to their axiological systems, enhancing their self-perception as players and weakening their self-perception in other social roles, for example, of a student, a friend, or an employee $[1,8$, $10,12,15,19]$.

Secondly, sport experiences enabled the players to perceive themselves in new situations. This included recognition of the extent of their capacity to function under intense effort and stress, as well as to meaningfully engage in interpersonal relations in the team, family, group of friends, school, and workplace. This knowledge helped the players identify barriers as they emerged and, then, attempt to overcome them. Also, sport boosted their motivation and resolve to persevere in their actions and ventures [2, 9, 10, 17, 21, 22].

Thirdly, sport fostered their sense of control over their lives. Through sport activity, they controlled their bodies, relating to them with greater awareness and care. At the same time, sport augmented their mental control, furnishing them with enlarged self-confidence, consolidating their sense of self-worth, and alleviating their insecurity and/or inferiority when engaging in interactions with both able-bodied individuals and individuals with disabilities. Practicing sport contributed to increasing the scope of their self-control and, thereby, promoted their greater involvement in practices of daily life. The resumption of such practices was also encouraged by the players' perseverance and good physical capability, developed through sport. This outcome was not undercut even by a greater risk of injury, trauma, or damage to health, to which the wheelchair basketball players were susceptible [2, 7, 17, 21, 22, 32-34].

Concluding, the findings from the study show that sport has an essential impact on positive self-perception in individuals with physical disabilities. Through sport activity, the physically disabled come to perceive themselves as more capable in daily life, more confident in their capacities, and more open to social interactions. Besides, sport may contribute to constructing new societal beliefs, in which individuals with disabilities are considered active partners in interpersonal relations, capable of taking care of themselves and others $[2,3$, $9,10,15]$.

Despite the fact that the present research deals with the situation of wheelchair basketball players in Po- land, it can be assumed that in the systems of values among players from other countries sport takes on the same kind, form, content, position, and function. An essential difference between the experience of players from various countries may therefore lie chiefly in the context (e.g. social, economic, political) in which they function and in which they realize particular values. Therefore, further research should take this context into account and investigate in particular its dependencies and relations with other values, such as health, physical ability, work, education, etc. Also, research concerning how sport is experienced from the perspective of different types and levels of disability or from the perspective of gender could prove interesting.

Knowledge about how individuals with disabilities experience sport may be effectively used to support rehabilitation processes and to educate the society toward integration of people with various psycho-physical dysfunctions. It may also serve as a tool in developing interpersonal competencies in people who interact with disabled individuals both privately (family, friends) and institutionally (public agencies, sports clubs, companies, etc.). Sport shows players with disabilities as fully fledged citizens, who only need help to overcome the barriers that lie in the way of their individual or social development [35].

\section{Disclosure statement}

No author has any financial interest or received any financial benefit from this research.

\section{Conflict of interest}

The authors state no conflict of interest.

\section{References}

1. Finkelstein V, French S. Toward a psychology of disability. In: Swain J, Finkelstein V, French S, Oliver M (eds.), Disabling barriers. Enabling environments. London: Sage; 1993; 9-16.

2. Blinde EM, McClung LR. Enhancing the physical and social self through recreational activity: accounts of individuals with physical disabilities. Adapt Phys Activ Q. 1997;14(4):327-344; doi: 10.1123/apaq.14.4.327.

3. Collins M, Kay T. Sport and social exclusion. London - New York: Routledge; 2003.

4. Goffman E. Stigma: notes of the management of spoiled identity. Englewood Cliffs: Prentice-Hall; 1963.

5. Grenier M, Collins K, Wright S, Kearns C. Perceptions of a disability sport unit in general physical education. Adapt Phys Activ Q. 2014;31(1):49-66; doi: 10.1123/ apaq:2013-0006.

6. Barnes C, Mercer G. Disability. Cambridge: Polity Press; 2003. 
7. Swain J, French S, Cameron C. Controversial issues in a disabling society. Maidenhead: Open University Press; 2005.

8. Berger RJ. Hoop dreams on wheels: disability and the competitive wheelchair athlete. London - New York: Routledge; 2010.

9. Martin JJ. Psychosocial aspects of youth disability sport. Adapt Phys Activ Q. 2006;23(1):65-77.

10. Thomas N, Smith A. Disability, sport and society. An introduction. London - New York: Routledge; 2009.

11. Rokeach M. Change and stability in American value systems, 1968-1971. Pub Opinion Q. 1974;38(2):222238; doi: 10.1086/268153.

12. Loland S. Fair play in sport. A moral norm system. London - New York: Routledge; 2013.

13. Dewey J. The quest for certainty. New York: Capricorn Books; 1960.

14. Parry J. Sport and Olympism: universals and multiculturalism. J Philos Sport. 2006;33(2):188-204; doi: 10.1080/00948705.2006.9714701.

15. DePauw KP, Gavron SJ. Disability sport. Champaign: Human Kinetics; 2005.

16. O'Gorman K. Saving sport: sport, society and spirituality. Dublin: Columbia Press; 2010.

17. Shields DLL, Bredemeier BJL. Character development and physical activity. Champaign: Human Kinetics; 1995.

18. Kluckhohn C. Values and value-orientations in the theory of action: an exploration in definition and classification. In: Parsons T, Shils EA (eds.), Toward a general theory of action: theoretical foundations for the social sciences. Cambridge: Harvard University Press; 1951; 388-433.

19. Spencer-Cavaliere N, Peers D. "What's the difference?" Women's wheelchair basketball, reverse integration, and the question(ing) of disability. Adapt Phys Activ Q. 2011;28(4):291-309; doi: 10.1123/apaq.28.4.291.

20. Morphy LY, Goodwin DL. The experience of choice in physical activity contexts for adults with mobility impairments. Adapt Phys Activ Q. 2012;29(2):132-150; doi: 10.1123/apaq.29.2.132.

21. Goodwin DL, Staples K. The meaning of summer camp experiences to youths with disabilities. Adapt Phys Activ Q. 2005;22(2):160-178; doi: 10.1123/apaq.22.2.160.

22. Fitzgerald H. Still feeling like a spare piece of luggage? Embodied experiences of (dis)ability in physical education and school sport. Phys Educ Sport Pedagogy. 2005; 10(1):41-59; doi: 10.1080/1740898042000334908.

23. Henderson KA, Bialeschki MD. Women and the meanings of physical recreation. Women Sport Phys Activ J. 1994;3(2):21-37; doi: 10.1123/wspaj.3.2.21.

24. Zitomer MR, Goodwin D. Gauging the quality of qualitative research in adapted physical activity. Adapt Phys Activ Q. 2014;31(3):193-218; doi: 10.1123/apaq.20130084.

25. Standal ØF. Phenomenology and adapted physical activity: philosophy and professional practice. Adapt Phys Activ Q. 2014;31(1):35-48; doi: 10.1123/apaq:2012-0064.
26. Bertalanffy L. General system theory: foundations, development, applications. New York: George Braziller; 1968.

27. Doliński W, Pezdek K. Sport in the system of values of people with disabilities; the example of wheelchair basketball players from the team "START" from Wrocław. In: Cynarski W, Kosiewicz J, Obodyński K (eds.), Sport in the context of social sciences. Rzeszów: Wydawnictwo Uniwersytetu Rzeszowskiego; 2012; 211-233.

28. Pezdek K, Doliński W. Basketball players on wheelchairs [in Polish]. Niepełnospr Rehabil. 2012;12(1):91-104.

29. Silverman D. Interpreting qualitative data. A guide to the principles of qualitative research. Los Angeles London - New Delhi: Sage; 2011.

30. Pezdek K, Doliński W. Theoretical and methodological aspects of the value-systems of the disabled people. Physiotherapy. 2010;18(4):60-68; doi: 10.2478/v10109010-0078-8.

31. Pezdek K, Doliński W. Jürgen Habermas and the dilemmas of experience of disability. Nurs Philos. 2017; 18(4):1-10; doi: 10.1111/nup.12171.

32. Doliński W. Disability and biographical control of the experienced lifeworld. Physiotherapy. 2012;20(4):4659; doi: 10.2478/v10109-012-0033-y.

33. Fitzgerald H. Disability and physical education. In: Kirk D, Macdonald D, O'Sullivan M (eds.), The handbook of physical education. London: Sage; 2006; 752766.

34. Kumar A. Disability, rehabilitation and social control: a Foucauldian perspective. Int J Hum Sci. 2011;8(2): 400-409.

35. Michaluk T, Pezdek K, Sobiech KA. Paralympic games in the context of social inclusion of people with disabilities [in Polish]. In: Kosiewicz J, Michaluk T, Pezdek K (eds.), Social sciences in sport and physical education [in Polish]. Wrocław: AWF; 2013; 278-285. 